\title{
25 Research Soure \\ Psychological distress and somatization in immigrants in primary health care practices.
}

\section{Rosa García-Sierra}

Primary Care Research Institute Jordi Gol

María Isabel Fernández-Cano ( $\nabla$ mariaisabel.fernandezc@uab.cat )

Universitat Autònoma de Barcelona https://orcid.org/0000-0002-4267-2345

Josep Maria Manresa-Domínguez

Primary Care Research Institut Jordi Gol

María Feijoo-Cid

Universitat Autònoma de Barcelona

\section{Eduard Moreno Gabriel}

Primary Care Research Institut Jordi Gol

Antonia Arreciado-Marañón

Universitat Autònoma de Barcelona Facultat de Veterinaria

Francesc Ramos-Roure

Institut Catala de la Salut

Jordi Segura

Ramon Llull University, Faculty of Psychology

Pere Torán-Monserrat

Primary Care Research Institut Jordi Gol

\section{Research article}

Keywords: Emigrants and Immigrants, Somatization disorders, Stress, Psychological, Primary Health Care, Vulnerable populations

Posted Date: November 2nd, 2020

DOI: https://doi.org/10.21203/rs.3.rs-30980/v2

License: (c) (i) This work is licensed under a Creative Commons Attribution 4.0 International License. Read Full License

Version of Record: A version of this preprint was published at Healthcare on December 13th, 2020. See the published version at https://doi.org/10.3390/healthcare8040557. 


\section{Abstract}

Background: The process of international migration causes a situation of vulnerability in people's health and greater difficulty in coping with disease. Furthermore, the adversities suffered during migration can trigger reactive signs of stress and cause anxious, depressive, confusional and somatic symptoms. This article studies the relationships between psychosocial risk, psychological distress and somatization in immigrants from 4 communities: Maghrebis, Sub-Saharans, South Americans and South Asians.

Methods: A cross-sectional study was carried out with questionnaires on 602 immigrants who were surveyed in the Primary Care Centres of an urban area of Catalonia. The instruments used were the Demographic Psychosocial Inventory (DPSI), the Brief Symptom Inventory (BSI) and the Somatic Symptom Inventory (SSI).

Results: The average psychosocial risk obtained was 0.35 , with the highest values in the sub-Saharan community. Psychological distress showed a mean value of 0.66 , with the sub-Saharan community scoring the lowest in all dimensions except depression. The average somatization values were 1.65, with the sub-Saharan community scoring the least. The female gender is a risk factor for somatization and psychological distress.

Conclusions: Perceived psychosocial risk is a predictor of psychological distress, but not somatization, suggesting that the use of more adaptive coping strategies could minimize the effect of the migration process on somatizations.

\section{Background}

The concept of migration is defined as "The movement of persons away from their place of usual residence, either across an international border or within a State" (1). The number of international migrants has increased in the last 50 years and it is estimated that 272 million people live in a country different from that of their birth, triple that of 1970, with $48 \%$ of them being women (2). In Spain, resident foreigners represent $10 \%$ of the population (3), the most recent being those from the migratory movement between 2000 and 2007 motivated by the demand for labour in the construction and domestic service sector mainly and which was later slowed by the economic crisis. (3). In 2016, there was a new rise in the number of registered resident foreigners caused by conflicts in their countries of origin and also by the reunification of families of immigrants already established in Spain. In Catalonia, population growth in recent years has been due to the immigration of the foreign population, which in 2019 represented $14 \%$ of the population (3).

The migratory process is a human experience that affects people's health and is an emerging public health problem that needs a response. Migrating involves high levels of emotional stress that affect health and that can manifest themselves physically and psychically. It is comprised of several phases, and in each one of them the health of immigrants is conditioned by different determinants. In the pre-migration phase, epidemiological profiles of the origin, environmental policies, and personal exposure to conflicts or human rights violations are decisive in defining the state of health. In the migratory movement phase, the duration, circumstances and conditions of the trip are the factors that most affect health. Finally, in the arrival phase, the migration policies of the destination country, access to health systems and the sensitivity of health professionals towards cultural and linguistic differences act as decisive factors on the health of migrants (4). Added to the determinants of the above-mentioned migratory process are others such as loneliness, insecurity, stress suffered during the migratory trip and cultural shock upon arrival in the new country, creating a situation in which the person will have difficulties anticipating and facing the impact of disease, thereby increasing their vulnerability (5). On the other hand, and even with having access to the health system, some groups of migrants may find it difficult to express their symptoms or understand therapeutic 
instructions, not only because of language barriers but also because the causal mechanisms of the disease may have different cultural constructs, especially the processes related to mental health. Furthermore, it should not be forgotten that having to move through the different healthcare levels is an added difficulty for people who come from systems of disorder (6).

All the afore-mentioned adversities can affect the person's homeostasis and the functioning of the hypothalamicpituitary-adrenal medullary axis, causing symptoms of psychological distress in the area of depression (sadness and crying), in the area of anxiety (irritability or insomnia), in the confusional area due to an increase in cortisol, as well as somatizations manifested by fatigue, osteoarticular discomfort or headache, among other symptoms. Somatic symptoms may appear in response to chronic stress and are also known as functional somatic symptoms (FSS), medically unexplained symptoms (MUS), bodily distress syndromes (BDS), or somatic symptom disorder (SSD). These names describe persistent physical symptoms that do not have an explanation. In relation to the manifestations associated with the migratory phenomenon, the Syndrome of Extreme Migratory Mourning was described in 1994, also called Ulysses Syndrome(7) in situations in which the chronic stress associated with the migration is extreme. Health professionals respond to somatic symptoms in a polarized way: they trivialize the symptoms due to the lack of objective evidence to explain them, due to ignorance of the syndrome or lack of cultural sensitivity, or they do not adequately diagnose the condition, classifying it as a depressive or psychotic illness, instead of a reactive picture of stress, thus elevating symptoms to the field of psychiatric pathology and adding a new stressor to the person (7), (8).

Consultations for recurrent symptoms of this type are especially relevant in primary care (9), since the deterioration in the quality of life of people who suffer from them leads to $60 \%$ more use of primary care services after hours (in primary Out-of-Hours care) than people who do not have these diagnoses (10). A recent systematic review argues that immigrants with somatization disorders perceive a greater need for the use of health services and greater difficulties in their daily lives than those who do not have them. However, there are differences in the prevalence of somatization disorders between different groups of immigrants, depending on culture, exposure to stress, explanatory models of the disease, coping and other individual variables (11).

The IOM (International Organization for Migration), the WHO and the Government of Spain organized a World Consultation on the Health of Migrants in 2010 (6). Four priorities were defined in it: monitoring the health of migrants, monitoring their equitable access to health services, developing health policies and programmes which are sensitive to the migrant population, and strengthening coordination and alliances between countries. Furthermore, it should be taken into account that migrants are not a homogeneous group and that increasing knowledge about their mental health, symptoms of psychological distress and psychosomatic manifestations, while attending separately to the different communities of origin would serve as a basis to better guide the healthcare services.

The research hypotheses were:

Psychosocial risk factors, psychological distress and somatizations show differences depending on the cultural community to which one belongs.

There are differences in the perception of psychosocial risk, psychological distress and somatizations which are related to gender.

Risk factors for psychological distress will consist of female gender, older age, less time residing in the host country, less academic education and psychosocial risk before and after migration. 
Risk factors for somatization will consist of female gender, older age, less time residing in the host country, less academic education and psychosocial risk before and after migration.

\section{Methods}

\section{Aim}

\section{Data and design}

A cross-sectional study was designed, whose protocol has been previously published, with questionnaires administered by trained multilingual interviewers (12).

The study population were immigrants who attended Primary Care Centres of an urban area of Barcelona (Spain). While they were in the waiting room of the health centre, they were offered the opportunity to participate in the survey. The sampling was consecutive between November 2011 and April 2013. The inclusion criteria were that they had lived in Europe for a period of between six months and ten years, that they were from countries in North Africa, subSaharan Africa, Central or South America or South Asia and that they agreed to participate voluntarily. An exclusion criterion was presenting some type of communicative difficulty, which despite the presence of a cultural mediator, did not allow for obtaining clear and understandable information.

The sample size was calculated accepting an alpha risk of 0.05 , a precision of $\pm 8 \%$ and an estimated prevalence of distress of $50 \%$, as the case of maximum indeterminacy, a sample size of 151 participants is representative of each of the 4 study groups.

\section{Instruments}

A form was prepared that collected sociodemographic data related to gender, marital status, educational level and length of residence in Spain. Psychosocial risk factors were collected through the 'Demographic Psychosocial Inventory' (DPSI) (13), an 85-item inventory comprised of two scales, one referring to pre-migration status and the other to post-migration status, and with three general indexes called global index, family structure and health problems, and five dimensions that act as risk factors that promote psychological distress in immigrants. All the scales score from 0 to 1 , where the highest scores represent states of poorer health or more psychosocial risk factors depending on the scale in question. The values that suggest clinical risk correspond to 0.44 for men and 0.48 for women.

Psychological distress was recorded using the 'Brief Symptom Inventory' (BSI) (14). In this investigation, the version adapted to Spanish (15) was used, consisting of 46 Likert-type response items from 0 to 4 , according to the manifestation of symptoms in the previous 30 days, where a higher score indicates poorer mental health. The version used has six scales to encompass the primary dimensions of psycho-pathological symptoms: depression, phobic anxiety, paranoid ideation, obsession-compulsion, somatization and hostility/aggressiveness, as well as an overall score that would be a measure of psychological distress. Alpha reliabilities for the six BSI scales showed optimal indices (between 0.70 and 0.91 ) in the psychometric study of the Spanish version.

To detect somatic symptoms, the 'Somatic Symptom Inventory' (SSI) was used (16), based on the DSM-III criteria for somatization disorders. It consists of 26 Likert-type response items from 0 to 4 , with higher scores representing greater intensity of symptoms. According to Tamayo et al. (17), scores $\leq 52$ represent minimal somatic discomfort and $>52$ moderate to severe discomfort. 


\section{Ethical considerations}

The confidentiality of the data obtained was absolute and scrupulous using no data which might identify the participants of the study. The data were filed in databases with totally anonymous information technology support and were wholly analysed by persons other than the interviewers. The interviews were carried out in an isolated room with a relaxed atmosphere favouring the free and sincere narrative of each interviewee after first having obtained written informed consent. If necessary, cultural mediators/facilitators were required to obtain such consent. The protocol of investigation has been reviewed and approved by the Ethical and Clinical Investigation Committee of the Primary Care Research Institute IDIAP Jordi Gol (Barcelona, Spain) on $21^{\text {st }}$ July 2010.

\section{Data analysis}

A univariate analysis was performed calculating absolute frequency and percentage in the categorical variables and mean and standard deviation in the quantitative ones. A bivariate analysis was performed using the ANOVA test and the $T$ test on the contrasts between variables. The predictive variables of psychosomatic symptomatology were evaluated with a multiple hierarchical regression, introducing the sociodemographic variables in the first step and the pre-migration and post-migration scales and the DPSI global indices in the second step using the PIN (0.05) and POUT (0.10) enter method. The multicollinearity of the data was analysed using the Variance Inflation Factor (VIF) and tolerance (18). VIF values less than 10 in regressions and tolerance values greater than 0.10 indicate that the explanatory variables do not show multicollinearity in the chosen model. The level of significance used was $p \leq 0.05$.

The analyses were performed with the SPSS statistical package for Windows, version 22.0.

\section{Results}

A total of 602 people participated, $50 \%$ women, belonging to four communities of different origins, $20 \%$ of South America (Bolivia, Ecuador, Colombia), 35\% of South Asia (Pakistan, Afghanistan, Bangladesh), 21\% of North African origin (Morocco, Tunisia, Algeria) and 24\% of sub-Saharan origin (Senegal, Gambia, Mali). Table 1 shows an exhaustive description of the sociodemographic characteristics of the participants according to their community of origin.

Table 1 Sociodemographic characteristics of the participants by community. 


\begin{tabular}{|c|c|c|c|c|c|}
\hline & $\begin{array}{l}\text { South America } \\
n=122\end{array}$ & $\begin{array}{l}\text { South Asia } \\
\mathrm{n}=212\end{array}$ & $\begin{array}{l}\text { Maghreb } \\
n=125\end{array}$ & $\begin{array}{l}\text { Sub-Sahara } \\
n=143\end{array}$ & $\begin{array}{l}\text { Total } \\
n=602\end{array}$ \\
\hline & n (\%) & n (\%) & n (\%) & n (\%) & n (\%) \\
\hline Age & $39.8(11.4)$ & $36.2(10.0)$ & $33.1(10.6)$ & $31.8(7.6)$ & $35.2(10.3)$ \\
\hline Men & $58(47.5 \%)$ & $120(56.6 \%)$ & $68(54.4 \%)$ & 55 (38.5\%) & $301(50.0 \%)$ \\
\hline \multicolumn{6}{|l|}{ Religion } \\
\hline Atheists & $6(4.9 \%)$ & $0(0.0 \%)$ & $0(0.0 \%)$ & $3(2.1 \%)$ & $9(1.5 \%)$ \\
\hline Muslims & $0(0.0 \%)$ & 190 (89.6\%) & $125(100 \%)$ & 125 (88.0\%) & $440(73.2 \%)$ \\
\hline Christians & $116(95.1 \%)$ & $0(0.0 \%)$ & $0(0.0 \%)$ & $14(9.9 \%)$ & $130(21.6 \%)$ \\
\hline Eastern & $0(0.0 \%)$ & $22(10.4 \%)$ & $0(0.0 \%)$ & $0(0.0 \%)$ & $22(3.7 \%)$ \\
\hline \multicolumn{6}{|l|}{ Level of studies } \\
\hline Without studies & $1(0.9 \%)$ & 28 (13.2\%) & 24 (19.2\%) & 41 (28.7\%) & 94 (15.6\%) \\
\hline Primary & $15(12.3 \%)$ & $123(58.0 \%)$ & $28(22.4 \%)$ & 45 (31.5\%) & $211(35.0 \%)$ \\
\hline Secondary & $29(23.8 \%)$ & $44(20.8 \%)$ & $26(20.8 \%)$ & $32(22.4 \%)$ & $131(21.8 \%)$ \\
\hline High school & 38 (31.1\%) & $13(6.1 \%)$ & 19 (15.2\%) & $6(4.2 \%)$ & $76(12.6 \%)$ \\
\hline Job training & $17(13.9 \%)$ & $0(0.0 \%)$ & $16(12.8 \%)$ & $9(6.3 \%)$ & $42(7.0 \%)$ \\
\hline University & $22(18.0 \%)$ & $4(1.9 \%)$ & $12(9.6 \%)$ & $10(7.0 \%)$ & $48(8.0 \%)$ \\
\hline \multicolumn{6}{|l|}{ Civil status } \\
\hline Single & $34(27.9 \%)$ & $58(27.4 \%)$ & $52(41.6 \%)$ & 45 (31.5\%) & $189(31.4 \%)$ \\
\hline With partner & $22(18 \%)$ & $0(0.0 \%)$ & $3(2.4 \%)$ & $0(0.0 \%)$ & 25 (4.2\%) \\
\hline Married & $46(37.7 \%)$ & $144(67.9 \%)$ & $55(44 \%)$ & $90(62.9 \%)$ & $335(55.6 \%)$ \\
\hline Separate & $9(7.4 \%)$ & $4(1.9 \%)$ & $1(0.8 \%)$ & $3(2.1 \%)$ & $17(2.8 \%)$ \\
\hline Divorced & $10(8.2 \%)$ & $5(2.4 \%)$ & $12(9.6 \%)$ & $5(3.5 \%)$ & $32(5.3 \%)$ \\
\hline Widow/er & $1(0.8 \%)$ & $1(0.5 \%)$ & $2(1.6 \%)$ & $0(0 \%)$ & $4(0.7 \%)$ \\
\hline \multicolumn{6}{|c|}{ Employment situation } \\
\hline Jobless & $45(36.9 \%)$ & 93 (43.9\%) & $53(42.4 \%)$ & $76(53.1 \%)$ & $267(44.4 \%)$ \\
\hline Street trading & $0(0.0 \%)$ & $0(0.0 \%)$ & $0(0.0 \%)$ & 15 (10.5\%) & 15 (2.5\%) \\
\hline Student & $4(3.3 \%)$ & $0(0.0 \%)$ & $13(10.4 \%)$ & $0(0.0 \%)$ & $17(2.8 \%)$ \\
\hline Housewife & $7(5.7 \%)$ & $45(21.2 \%)$ & $14(11.2 \%)$ & $9(6.3 \%)$ & 75 (12.5\%) \\
\hline Active worker & $63(51.6 \%)$ & 72 (34.0\%) & 44 (35.2\%) & $43(30.1 \%)$ & $222(36.9 \%)$ \\
\hline Pensioner & $2(1.6 \%)$ & $2(0.9 \%)$ & $1(0.8 \%)$ & $0(0.0 \%)$ & $5(0.8 \%)$ \\
\hline Others & $1(0.8 \%)$ & $0(0.0 \%)$ & $0(0.0 \%)$ & $0(0.0 \%)$ & $1(0.2 \%)$ \\
\hline
\end{tabular}




\begin{tabular}{|c|c|c|c|c|c|}
\hline \multicolumn{6}{|l|}{ Spanish knowledge } \\
\hline Speak and write correctly & $117(97.5 \%)$ & $17(8.1 \%)$ & $54(43.5 \%)$ & $41(28.9 \%)$ & $229(38.4 \%)$ \\
\hline Speaks and writes with difficulty & $2(1.7 \%)$ & $73(34.6 \%)$ & $28(22.6 \%)$ & $43(30.3 \%)$ & $146(24.5 \%)$ \\
\hline Speak but not write & $1(0.8 \%)$ & $54(25.6 \%)$ & $34(27.4 \%)$ & $43(30.3 \%)$ & $132(22.1 \%)$ \\
\hline Not speak or write it & $0(0.0 \%)$ & $67(31.8 \%)$ & $8(6.5 \%)$ & $15(10.6 \%)$ & $90(15.1 \%)$ \\
\hline Years since migration & $9.4(3.3)$ & $5.2(3.0)$ & $6.6(3.0)$ & $5.8(2.6)$ & $6.5(3.4)$ \\
\hline \multicolumn{6}{|l|}{ Number of children } \\
\hline None & $31(25.4 \%)$ & $86(40.6 \%)$ & $65(52.0 \%)$ & $51(35.7 \%)$ & $233(38.7 \%)$ \\
\hline $1-2$ & $68(55.7 \%)$ & $54(25.5 \%)$ & $29(23.2 \%)$ & $48(33.6 \%)$ & $199(33.1 \%)$ \\
\hline $3-4$ & $18(14.8 \%)$ & $41(19.3 \%)$ & $23(18.4 \%)$ & $35(24.5 \%)$ & $117(19.4 \%)$ \\
\hline 5 or more & $5(4.1 \%)$ & $31(14.6 \%)$ & $8(6.4 \%)$ & $9(6.3 \%)$ & $53(8.8 \%)$ \\
\hline
\end{tabular}

Regarding psychosocial risk factors, the global DPSI index was 0.35 , showing differences between the four communities studied with people of sub-Saharan origin perceiving greater psychosocial risk according to the a posteriori contrasts carried out (see Table 2).

Regarding the symptoms of psychological distress, Table 2 shows a description of the different scales of the BSI, as well as the overall score differentiated by communities, highlighting that sub-Saharan immigrants have lower levels of psychological distress on the somatization, hostility, paranoid ideation and anxiety scales. On the depression scale the lowest values were obtained by the South American community.

Psychosomatic symptoms evaluated with a single SSI score show differences between communities, with values ranging from 36 to 47, below the cut-off point indicating moderate somatic discomfort. Sub-Saharan immigrants score less than the other communities on somatization.

Table 2 Questionnaires' description by community. N=602 


\begin{tabular}{|c|c|c|c|c|c|c|c|}
\hline & $\begin{array}{l}\text { South } \\
\text { America }\end{array}$ & South Asia & Maghreb & $\begin{array}{l}\text { Sub- } \\
\text { Sahara }\end{array}$ & Total & \multirow[t]{2}{*}{$\mathbf{F}$} & \multirow[t]{2}{*}{ Sig. } \\
\hline & $\begin{array}{l}\text { M/item } \\
\text { (SD/item) }\end{array}$ & $\begin{array}{l}\text { M/item } \\
\text { (SD/item) }\end{array}$ & $\begin{array}{l}\text { M/item } \\
\text { (SD/item) }\end{array}$ & $\begin{array}{l}\text { M/item } \\
\text { (SD/item) }\end{array}$ & $\begin{array}{l}\text { M/item } \\
\text { (SD/item) }\end{array}$ & & \\
\hline \multicolumn{8}{|l|}{ DPS|* } \\
\hline Premigration scales & $0.10(0.19)$ & $0.16(0.23)$ & $0.13(0.22)$ & $0.15(0.23)$ & $0.14(0.22)$ & 2.30 & 0.077 \\
\hline Postmigration scales & $0.43(0.35)$ & $0.34(0.33)$ & $0.35(0.36)$ & $0.32(0.33)$ & $0.36(0.35)$ & 2.73 & 0.043 \\
\hline Index Global DPSI & $0.36(0.09)$ & $0.33(0.09)$ & $0.34(0.07)$ & $0.38(0.07)$ & $0.35(0.09)$ & 11.38 & $<.001$ \\
\hline \multicolumn{8}{|l|}{ BSI** } \\
\hline Depression & $0.78(74)$ & $0.89(0.95)$ & $1.09(0.76)$ & $1.09(0.73)$ & 0.95 & 4.79 & 0.003 \\
\hline Phobic anxiety & $0.30(35)$ & $0.43(0.71)$ & $0.35(0.53)$ & $0.17(0.24)$ & 0.32 & 6.69 & $<.001$ \\
\hline Paranoid Ideation & $0.72(63)$ & $0.88(0.97)$ & $0.87(0.69)$ & $0.52(0.42)$ & 0.76 & 7.60 & $<.001$ \\
\hline $\begin{array}{l}\text { Obsession- } \\
\text { compulsion }\end{array}$ & $0.65(53)$ & $0.82(0.80)$ & $0.93(0.68)$ & $0.67(0.39)$ & 0.77 & 5.32 & .001 \\
\hline Somatization & $0.72(69)$ & $0.75(1.00)$ & $0.72(0.69)$ & $0.36(0.35)$ & 0.64 & 8.91 & $<.001$ \\
\hline Hostility/aggressivity & $0.39(58)$ & $0.36(0.69)$ & $0.23(0.45)$ & $0.13(0.25)$ & 0.29 & 7.13 & $<.001$ \\
\hline $\begin{array}{l}\text { General Severity } \\
\text { Index }\end{array}$ & $0.62(50)$ & $0.72(0.80)$ & $0.75(0.54)$ & $0.53(0.29)$ & 0.66 & 4.05 & 0.007 \\
\hline SSI*** & $\begin{array}{l}1.68 \\
(0.63)\end{array}$ & $1.82(1.04)$ & $\begin{array}{l}1.63 \\
(0.52)\end{array}$ & $1.39(0.30)$ & $1.65(0.75)$ & 9.99 & $<.001$ \\
\hline
\end{tabular}

Note: M/item: Mean divided by the number of items; $S D /$ item: Standard deviation divided by the number of items *Score from 0 to 1

** Score from 0 to 4

$\star \star \star$ Score from 0 to 4

When comparing the pre-migration scales and the post-migration scales according to gender, differences between the two genders were observed with women having the worst results. However, the overall psychosocial risk score does not vary.

Regarding the symptoms of psychological distress and psychosomatic symptomology, women showed higher scores on all scales (see Table 3).

Table 3 Questionnaires' description by gender. 


\begin{tabular}{|c|c|c|c|c|}
\hline & Women & Men & \multirow[t]{2}{*}{$\mathbf{F}$} & \multirow[t]{2}{*}{ Sig. } \\
\hline & M/item (SD/item) & M/item (SD/item) & & \\
\hline \multicolumn{5}{|l|}{ DPSI* } \\
\hline Premigration scales & $0.20(0.25)$ & $0.07(0.18)$ & 54.62 & $<.001$ \\
\hline Postmigration scales & $0.45(0.33)$ & $0.26(0.34)$ & 50.32 & $<.001$ \\
\hline Index Global DPSI & $0.35(0.10)$ & $0.36(0.08)$ & 1.49 & 0.223 \\
\hline \multicolumn{5}{|l|}{ BSI** } \\
\hline Depression & $1.15(0.90)$ & $0.76(0.70)$ & 34.90 & $<.001$ \\
\hline Phobic anxiety & $0.43(0.62)$ & $0.22(0.41)$ & 22.76 & $<.001$ \\
\hline Paranoid Ideation & $0.87(0.82)$ & $0.66(0.68)$ & 11.62 & 0.001 \\
\hline Obsession-compulsion & $0.90(0.72)$ & $0.64(0.55)$ & 24.71 & $<.001$ \\
\hline Somatization & $0.86(0.90)$ & $0.43(0.57)$ & 49.02 & $<.001$ \\
\hline Hostility/aggressivity & $0.38(0.63)$ & $0.20(0.44)$ & 16.70 & $<.001$ \\
\hline General Severity Index & $0.80(0.68)$ & $0.52(0.48)$ & 34.01 & $<.001$ \\
\hline SSI*** & $1.89(0.88)$ & $1.42(0.48)$ & 64.24 & $<.001$ \\
\hline
\end{tabular}

Note: M/item. mean divided by the number of items; SD/item. standard deviation divided by the number of items *Score from 0 to 1

** Score from 0 to 4

$\star \star \star$ Score from 0 to 4

The regression with the psychological distress outcome variable measured with the global BSI score provides a model that explains $12.5 \%$ of the variance of psychological distress in women and a $9.3 \%$ in men. The predictors in the model are the variables of post-migration scales, global DPSI index, and pre-migration scales with a positive relation, to be married and the number of years since migration with negative $\beta$ (see Table 4). Being the predictors different in women and men. Table 4 shows these results disaggregated by gender.

Table 4 Hierarchical lineal regressions (Enter). Outcome variable BSI 


\begin{tabular}{|c|c|c|c|c|c|c|c|c|c|}
\hline & \multicolumn{5}{|c|}{ Outcome variable BSI Women } & \multicolumn{4}{|c|}{ Outcome variable BSI Men } \\
\hline & \multicolumn{5}{|c|}{ Collinearity statistics } & \multicolumn{4}{|c|}{ Collinearity statistics } \\
\hline & B & $p$ & Tolerance & FIV & & $B$ & $p$ & Tolerance & FIV \\
\hline Marital status & -0.180 & 0.003 & 0.797 & 1.255 & $\begin{array}{l}\text { Premigration } \\
\text { scales }\end{array}$ & 0.130 & 0.040 & 0.791 & 1.264 \\
\hline $\begin{array}{l}\text { Years after } \\
\text { migration }\end{array}$ & -0.155 & 0.020 & 0.672 & 1.489 & $\begin{array}{l}\text { Postmigration } \\
\text { scales }\end{array}$ & 0.169 & 0.009 & 0.769 & 1.300 \\
\hline $\begin{array}{l}\text { Postmigration } \\
\text { scales }\end{array}$ & 0.158 & 0.017 & 0.685 & 1.461 & & & & & \\
\hline $\begin{array}{l}\text { Index Global } \\
\text { DPSI }\end{array}$ & 0.180 & 0.007 & 0.668 & 1.498 & & & & & \\
\hline $\mathrm{R}^{2}$ & 0.125 & & & & $\mathrm{R}^{2}$ & 0.093 & & & \\
\hline
\end{tabular}

A second hierarchical regression was performed with a psychosomatic symptomology outcome variable measured with the SSI. The chosen model explains $22.5 \%$ of the variance in psychosomatic symptomology in women and $21,6 \%$ in men. Predictor variables are age, pre-migration scales, post-migration scales having a positive relation, and number of years since migration with negative $\beta$. The global DPSI index is no longer a predictor of somatization (see Table 4). Table 5 shows these results disaggregated by gender.

Table 5 Hierarchical lineal regressions (Enter). Outcome variable SSI

\begin{tabular}{|lllllllllll|}
\hline \multicolumn{4}{|c}{ Outcome variable SSI Women } & \multicolumn{5}{c|}{ Outcome variable SSI Men } \\
\hline & Collinearity statistics & & & \multicolumn{4}{c|}{ Collinearity statistics } \\
\hline & $B$ & $p$ & Tolerance & FIV & & $B$ & $p$ & Tolerance & FIV \\
\hline Age & 0.222 & 0.002 & 0.523 & 1.911 & Age & 0.185 & 0.008 & 0.561 & 1.782 \\
\hline $\begin{array}{l}\text { Years after } \\
\text { migration }\end{array}$ & -0.148 & 0.017 & 0.685 & 1.459 & $\begin{array}{l}\text { Premigration } \\
\text { scales }\end{array}$ & 0.233 & $<.001$ & 0.794 & 1.259 \\
\hline $\begin{array}{l}\text { Premigration } \\
\text { scales }\end{array}$ & 0.206 & 0.001 & 0.690 & 1.448 & $\begin{array}{l}\text { Postmigration } \\
\text { scales }\end{array}$ & 0.222 & $<.001$ & 0.773 & 1.293 \\
\hline $\begin{array}{l}\text { Postmigration } \\
\text { scales }\end{array}$ & 0.214 & 0.001 & 0.694 & 1.440 & & & & & & \\
\hline $\mathbf{R}^{2}$ & 0.225 & & & & $\mathbf{R}^{2}$ & 0.216 & & & \\
\hline
\end{tabular}

\section{Discussion}

The participants in this research come mainly from nine countries (Bolivia, Ecuador, Colombia, Morocco, Tunisia, Algeria, Senegal, Gambia, Mali) grouped into four different communities: South American, sub-Saharan, Maghrebi and Southern Asian. The cultural differences between these groups are important, although the most distinctive fact is the language: only the South American community has the same language (Spanish) as the host country. 
The first hypothesis that was posed was that the fact of belonging to different cultural communities conditioned the perception of psychosocial risk, psychological distress and somatic symptoms. The results obtained would allow us to accept this hypothesis since there are significant differences in the perception of psychosocial risk, as well as in all the scales of psychological distress (BSI) and in the somatization scale (SSI). In addition, the a posteriori contrasts allow us to affirm a clearly differentiated behaviour of sub-Saharan immigrants compared with the other communities since they perceive a greater psychosocial risk, although they exhibit fewer symptoms of psychological and psychosomatic distress.

The second hypothesis that was posed was the existence of differences in the perception of psychosocial risk, psychological distress and somatizations due to gender. The results partially support this hypothesis since in all the evaluation scales, women scored significantly higher than men, showing greater pre-migration and post-migration psychosocial risk, worse psychological health and more somatization disorders. These results are in the same line as the findings of other investigations carried out with the immigrant population in which the female gender presents greater severity of somatic symptoms (21), (22). Female gender is also shown as a significant variable in anxiety, mood disorders, eating disorders and somatization, not only in immigrant communities but also in the indigenous population (9) . However, the score on the global psychosocial risk scale does not show differences between men and women. This was an unexpected result as the pre-migration and post-migration scales are part of the global scale. This difference is determined to be because the global scale adds five single items under the construct "conflict reaction", which act to moderate psychosocial risk and as a result turn out to be more adaptive coping strategies than those used by men, thereby equalizing the global perception of psychosocial risk.

The third hypothesis supposed that the risk factors for greater psychological distress are female gender, older age, less time residing in the host country, less academic education and psychosocial risk before and after migration. The separate analysis of men and women showed differences in the predictors of psychological distress. In men, the premigration and post-migration conditions appear in the model, however in women the post-migration scales, the global DPSI index, the years since migration and being married appear. Therefore, the results partially support the hypothesis since education and older age are not significant, the time residing in the host country and psychosocial risk are significant only in women. Furthermore, to be married appears as predictor of psychological distress in women. The literature shows contradictory results in relation to the effect of educational level of people who emigrate. Having a university degree was a predictor of worse general health among refugee adults in Australia (23) while it was a protective factor in refugees, where having higher education predicted fewer medical conditions (24) and less psychological distress (25). The pre-migration conditions in some studies, had appeared as a strong predictor of depression and other psychological disorders (26). The study by Jamil et al.(24) highlights that the premigration situation behaved differently in refugees and immigrants, with refugees being the main risk factor for having worse self-perceived health, whereas it did not influence the self-perceived health of the immigrant population. Regarding pre-migration conditions, Li and Anderson (27) demonstrated that the influence of the pre-migration situation on psychological symptoms was mediated by perceived discrimination, since immigrants with traumatic experiences perceive the world as a dangerous place. In other contexts, these negative beliefs about the lack of benevolence in the world lead to increased levels of vigilance, which in turn increases stress (28). In relation to the effect of marital status, which appears with a negative relationship with psychological distress in women, the literature also shows contradictory results, Aragona found a higher risk of somatization in married people (29), while Shiroma didn't find significant association between somatization and marital status (30) and Ristner found less somatization in married people (31). 
The last hypothesis proposed as somatization risk factors the female gender, older age, less time residing in the destination country, lesser academic education and the psychosocial risk before and after migration. This hypothesis is partially supported since academic education is not significant and the years since the migration is significant only in women. Evidence shows that academic education behaves ambivalently, the lower the formal education, the higher the prevalence of somatization (32), or with greater levels of education than high school, greater somatization in Russian and Hispanic immigrants (30).

The global DPSI scale is not significant for the somatization outcome variable, taking into account that the other dimensions of the perception of psychosocial risk variable, if they are significant, would be indicative that coping strategies would influence the impact that psychosocial risk may have in the onset of somatization disorders. In line with this argument, in 2008, Sachs et al.(33) explored coping strategies and stress in Tibetan refugees in India who had been exposed to traumatic situations, reporting that coping strategies acted as mediators between lived traumatic experiences and decreased somatic symptoms.

\section{Strengths and limitations of the study}

This study is the first approach to the study of somatization disorders and psychological distress of immigrants of different origins carried out in Spain. The main strength of the research is found in the composition of the sample, not only due to its high number but also due to being composed of people from 12 countries that contributed, in the year in which the research was carried out, $42 \%$ of immigrants to Catalonia (34). The findings are applicable to immigrant populations residing in Europe and specially in the Mediterranean area (France, Italy, Greece, Portugal) because these countries have similar migratory patterns (35).

There are some limitations in the study related to the questionnaires, the main one being the language barrier for some of the participants since Spanish versions of the questionnaires were used. However, to minimize possible comprehension deficits, multilingual interviewers participated as cultural mediators when necessary. Secondly, only the BSI questionnaire had a validated version into Spanish, the SSI and the DPSI were adapted to Spanish following a translation and reverse translation process. Thirdly, the length of the questionnaires required an investment of between 30 and 40 minutes, therefore some fatigue may have affected completing the questionnaires. However, the fact that they were carried out by interviewers and were not self-administered potentially reversed part of this effect.

\section{Conclusions}

Despite the limitations, this research contributes to the limited literature on somatization disorders and psychological distress in different immigrant communities.

Sub-Saharan immigrants perceive a greater psychosocial risk than other cultural groups, although they show lower levels of psychological distress and lower levels of somatization.

Being a woman and being older are risk factors for presenting greater psychological distress and more psychosomatic symptoms. In contrast, the time that has passed since migration is a protective factor in women, but not in men.

The fact that perception of psychosocial risk is a predictor of psychological distress, but is not a predictor of somatic symptoms, could indicate that the coping strategies that are included in the global DPSI scale may have an influence on reducing the development of somatization disorders. Working on the coping strategies of people who have 
recently migrated (newcomers) might improve the presentation of psychosomatic manifestations, especially in women.

\section{List Of Abbreviations}

DPSI: Demographic Psychosocial Inventory

BSI: Brief Symptom Inventory

SSI: Somatic Symptom Inventory

FSS: Functional Somatic Symptoms

MUS: Medically Unexplained Symptoms

BDS: Bodily Distress Syndromes

SSD: Somatic Symptom Disorder

IOM: International Organization for Migration

WHO: World Health Organization

DPSI: Demographic Psychosocial Inventory

BSI: Brief Symptom Inventory

SSI: Somatic Symptom Inventory

VIF: Variance Inflation Factor

\section{Declarations}

\section{Acknowledgements}

The authors would like to thank all of the study participants for their contributions to this research.

\section{Authors' contributions}

Contributed to the original idea: JMMD, MIFC, MFC, FRR, JSB, PTM

Designed de questionnaire: JMMD, MIFC

Conducted Research: JMMD, MIFC, MFC, FRR, JS, PTM

Conducted the initial analysis: JMMD, MIFC, RGS

Wrote the first draft of the manuscript: RGS

Made critical comments during the process of writing: All authors

Approved the final version of the manuscript: All authors 


\section{Funding}

This project has received a grant 'Gonçal Calvo', from the Acadèmia de Ciències Mèdiques i de la Salut de Catalunya i Balears (Mataró, Spain) 2010.

Honourable mention of the 6th 2010 Award on Primary Health Research of the Barcelona Health Region.

\section{Availability of data and materials}

Not applicable.

\section{Ethics approval and consent to participate}

The study was approved by the Ethical and Clinical Investigation Committee of the Primary Care Research Institute IDIAP Jordi Gol (Barcelona, Spain). There was an informed consent attached to the questionnaire that the participants signed.

\section{Consent for publication}

Not applicable.

\section{Competing interests}

The authors declare that they have no competing interests.

\section{References}

1. International Organization for Migration. Glossary on Migration. [Internet]. 2019. [cited 2020 May 16]. Available from: https://www.iom.int/glossary-migration-2019

2. IOM Online Bookstore. World Migration Report 2020 [Internet]. 2020. Available from: https://publications.iom.int/books/world-migration-report-2020

3. INE. España en cifras 2019 [Internet]. Madrid; 2019. Available from: http://www.ine.es/prodyser/espa_cifras

4. Gushulak B, Weekers J, MacPherson D. Migrants in a globalized world - health threats, risks and challenges: an evidence-based framework. Emerg Health Threats J. 2008;2.

5. Grabovschi C, Loignon C, Fortin M. Mapping the concept of vulnerability related to health care disparities: a scoping review [Internet]. 2013. Available from: http://www.biomedcentral.com/1472-6963/13/94

6. World Health Organization IO for M y G de E. Health of migrants: the way forward - report of a global consultation. Madrid, Spain. 2010. 119 p.

7. Achotegui Loizate J, López A, Morales Suárez-Varela MM, Espeso D, Achotegui A. Social and demographic study on immigrants with the Ulysses syndrome: Study on 1.110 immigrants attended at SAPPIR in Barcelona. Norte Salud Ment [Internet]. 2015;13(52):70-8. Available from: https://dialnet.unirioja.es/servlet/articulo? codigo $=5191741$ info=resumen\&idioma $=$ SPA

8. Greco M. Pragmatics of explanation: Creative accountability in the care of 'medically unexplained symptoms'. Sociol Rev. 2017;65(2_suppl):110-29.

9. Salinero-Fort MA, Jiménez-García R, de Burgos-Lunar C, Chico-Moraleja RM, Gómez-Campelo P. Common mental disorders in primary health care: differences between Latin American-born and Spanish-born residents in Madrid, Spain. Soc Psychiatry Psychiatr Epidemiol. 2015 Mar 1;50(3):429-43. 
10. Leutgeb R, Berger S, Szecsenyi J, Laux G. Patients with somatoform disorders: More frequent attendance and higher utilization in primary out-of-hours care? PLoS One. 2018 Aug 1;13(8).

11. Lanzara R, Scipioni M, Conti C. A clinical-psychological perspective on somatization among immigrants: A systematic review. Front Psychol. 2019;9(JAN).

12. Torán-Monserrat $P$, Cebrià-Andreu J, Arnau-Figueras J, Segura-Bernal J, Ibars-Verdaguer A, Massons-Cirera J, et al. Level of distress, somatisation and beliefs on health-disease in newly arrived immigrant patients attended in primary care centres in Catalonia and definition of professional competences for their most effective management: PROMISE Project. BMC Fam Pract [Internet]. 2013 May 4 [cited 2018 Nov 28];14:54. Available from: https://doi.org/10.1186/1471-2296-14-54

13. Ritsner M, Rabinowitz J, Slyuzberg M. The Demographic Psychosocial Inventory: A New Instrument to Measure Risk Factors for Adjustment Problems Among Immigrants. Refuge. 1995;14(9):8-16.

14. Derogatis leonard R. Inventario Breve de 18 Sintomas (BSI-18) [Internet]. Madrid; 2013. Available from: https://www.cop.es/uploads/PDF/2015/BSI-Pearson.pdf

15. Ruipérez MÁ, Ibáñez MI, Lorente E, Moro M, Ortet G. Psychometric Properties of the Spanish Version of the BSI. Eur J Psychol Assess [Internet]. 2001 Sep [cited 2018 Nov 28];17(3):241-50. Available from: https://econtent.hogrefe.com/doi/10.1027//1015-5759.17.3.241

16. Escobar JI, Rubio-Stipec M, Canino G, Karno M. Somatic symptom index (SSI): a new and abridged somatization construct. Prevalence and epidemiological correlates in two large community samples. J Nerv Ment Dis [Internet]. 1989 Mar;177(3):140-6. Available from: http://www.ncbi.nlm.nih.gov/pubmed/2918297

17. Tamayo JM, Román K, Fumero JJ, Rivas M. The level of recognition of physical symptoms in patients with a major depression episode in the outpatient psychiatric practice in Puerto Rico: An observational study. BMC Psychiatry [Internet]. 2005 Dec 20;5(1):28. Available from: https://doi.org/10.1186/1471-244X-5-28

18. Belsley DA, Kuh E, Welsch RE. Regression diagnostics: identifying influential data and sources of collinearity. John Wiley, editor. New York, USA: Wiley; 2004. 292 p.

19. The Lancet Public Health. No public health without migrant health. Lancet Public Heal [Internet]. 2018;3(6):e259. Available from: http://dx.doi.org/10.1016/S2468-2667(18)30101-4

20. Bhugra D, Tasman A, Pathare S, Priebe S, Smith S, Torous J, et al. The WPA-Lancet Psychiatry Commission on the Future of Psychiatry. The Lancet Psychiatry. 2017;4(10):775-818.

21. Aragona M, Rovetta E, Pucci D, Spoto J, Villa AM. Somatization in a primary care service for immigrants. Ethn Heal. 2012 Oct 1;17(5):477-91.

22. Morawa E, Dragano N, Jöckel KH, Moebus S, Brand T, Erim Y. Somatization among persons with Turkish origin: Results of the pretest of the German National Cohort Study. J Psychosom Res. 2017 May 1;96:1-9.

23. Dowling A, Enticott J, Kunin M, Russell G. The association of migration experiences on the self-rated health status among adult humanitarian refugees to Australia: An analysis of a longitudinal cohort study. Int J Equity Health. 2019 Aug 22;18(1).

24. Jamil H, Barkho E, Broadbridge CL, Ventimiglia M, Arnetz JE, Lami F, et al. Self-rated Health and Medical Conditions in Refugees and Immigrants from the Same Country of Origin. Iraqi J Med Sci [Internet].

2015;13(2):108-19. Available from:

http://www.ncbi.nlm.nih.gov/pubmed/26644795\%0Ahttp://www.pubmedcentral.nih.gov/articlerender.fcgi? artid=PMC4669974

25. Myhrvold T, Småstuen MC. The mental healthcare needs of undocumented migrants: an exploratory analysis of psychological distress and living conditions among undocumented migrants in Norway. J Clin Nurs. 2017;26(5-

Page 15/16 
6):825-39.

26. Fortuna LR, Porche M V., Alegria M. Political violence, psychosocial trauma, and the context of mental health services use among immigrant Latinos in the United States. Ethn Heal. 2008;13(5):435-63.

27. Li M, Anderson JG. Pre-migration Trauma Exposure and Psychological Distress for Asian American Immigrants: Linking the Pre- and Post-migration Contexts. J Immigr Minor Heal. 2016;18(4):728-39.

28. Lilly MM, Valdez CE, Graham-Bermann SA. The mediating effect of world assumptions on the relationship between trauma exposure and depression. J Interpers Violence. 2011;26(12):2499-516.

29. Aragona M, Monteduro MD, Colosimo F, Maisano B, Geraci S. Effect of Gender And Marital Status on Somatization Symptoms of Immigrants From Various Ethnic Groups Attending a Primary Care Service. Ger J Psychiatry · [Internet]. 2008; Available from: http://www.gjpsy.uni-goettingen.xn--de-1ea

30. Shiroma PR, Alarcon RD. Time for healing: somatization among chronically mentally immigrants. J Cult Divers. 2011;18(1):3-7.

31. Ritsner M, Ponizovsky A, Kurs R, Modai I. Somatization in an Immigrant Population in Israel: A Community Survey of Prevalence, Risk Factors, and Help-Seeking Behavior [Internet]. Vol. 157, Am J Psychiatry. 2000 [cited 2018 Nov 28]. Available from: https://ajp.psychiatryonline.org/doi/pdf/10.1176/appi.ajp.157.3.385

32. Mak WWS, Zane NWS. The phenomenon of somatization among community Chinese Americans. Soc Psychiatry Psychiatr Epidemiol. 2004;39(12):967-74.

33. Sachs E, Rosenfeld B, Lhewa D, Rasmussen A, Keller A. Entering Exile: Trauma, Mental Health, and Coping Among Tibetan Refugees Arriving in Dharamsala, India. J ofTraumatic Stress. 2008;21(2):199-208.

34. Idescat. Població estrangera per països. Catalunya [Internet]. 2019 [cited 2020 May 16]. Available from: https://www.idescat.cat/poblacioestrangera/?b=12

35. Eurostat. Migration and migrant population statistics. [cited 2020 Oct 23]. Avalaible from: https://ec.europa.eu/eurostat/statistics-

explained/index.php/Migration_and_migrant_population_statistics\#Migration_flows:_Immigration_to_the_EU27_from_non-member_countries_was_2.4_million_in_2018 